\title{
Are Private Health Insurance Subscribers Unsatisfied with the Spanish National Health System?
}

\author{
Joan Costa-Font ${ }^{\mathrm{a}, \mathrm{c}}$ and Mireia Jofre-Bonet ${ }^{\mathrm{b}}$ \\ ${ }^{a}$ LSE Health, London School of Economics, London, U.K. \\ E-mail: J.Costa-Font@1se.ac.uk \\ ${ }^{\mathrm{b}}$ Department of Economics, Social Sciences Building D307, City University, Northampton Square, London \\ EC1V 0HB, U.K. \\ E-mail: mireia.jofre-bonet@city.ac.uk \\ ${ }^{\mathrm{c}}$ Departament de Teoria Econòmica, Universitat de Barcelona, Catalonia, Spain
}

The percentage of population having supplementary private health insurance (PHI) is related to the perceived quality of the National Health System (NHS). In turn, PHI purchase decisions influence the NHS quality given that the number of PHI subscribers determines NHS quality indicators related to congestion. On the other hand, being satisfied with the NHS includes an assessment of the NHS as a whole that goes beyond the mere perception of its quality. This paper estimates the probabilities of purchasing PHI and of being satisfied with the NHS as two simultaneous processes taking into account that NHS quality may influence but also be influenced by these two outcomes. We use data from a Spanish representative survey released in 2002. Following this empirical strategy we find that: (1) the likelihood of having PHI and being satisfied with the NHS is negatively and simultaneously associated; and, (2) naïve estimation models may be underestimating the impact of the NHS perceived quality on the likelihood of purchasing PHI.

The Geneva Papers (2006) 31, 650-668. doi:10.1057/palgrave.gpp.2510102

Keywords: health care satisfaction; private health insurance; health care quality; partial opting-out

JEL classification: I1; G1

\section{Introduction}

In countries with a National Health System (NHS) such as Spain, the vast majority of health care provided by public sector and private health insurance (PHI) organizations stand as partial substitutes. While the NHS provides health care on a uniform basis and negligible costs after the payment of general taxes, PHI purchase means holding "double coverage" for certain health services - normally for non-elective care - in exchange for the payment of an annual insurance premium. Although those individuals might still use the NHS and continue paying taxes, ${ }^{1}$ one could interpret purchasing PHI as indicative of a predisposition to "partially" opt out from the NHS.

Aggregate cross-country evidence points towards some "anecdotal positive association" between dissatisfaction with the NHS and the extension of the private health care sector, as illustrated in Figure 1. Although the association between

\footnotetext{
${ }^{1}$ López-Nicolás et al. (2000).
} 


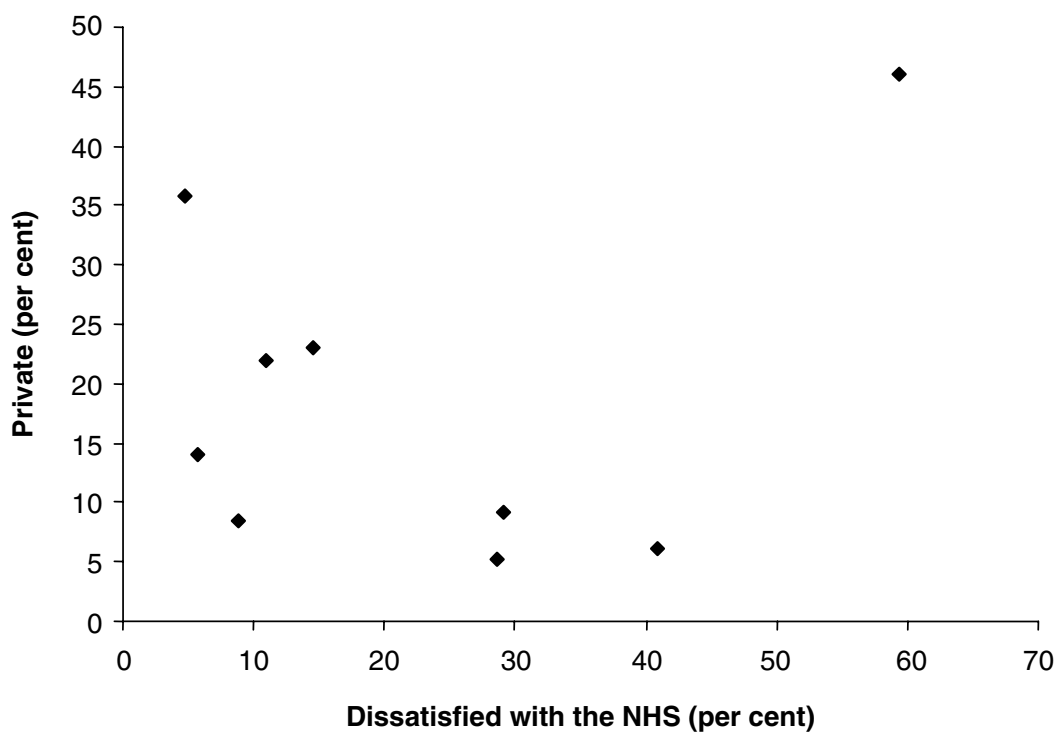

Figure 1. Health system dissatisfaction and private health funding in some European countries. Source: OECD Database and Eurobarometer 1998. Countries included are Austria, Denmark, France, Germany, Luxembourg, Spain, UK, Portugal, and Ireland.

measures of overall health system assessment and private sector development is far from straightforward and should be treated with caution. The development of the market for supplementary PHI stands as a possible "side evidence" signalling NHS quality shortages.

NHS satisfaction and perceived quality are related but not necessarily coincident. We argue that NHS satisfaction results from an overall "socio-political evaluation" of the NHS that goes beyond individually experienced quality of care. In particular, the latter relies on the specific characteristics of the process of health care delivery (waiting times, patient satisfaction assessments, etc.). Instead, as some studies reveal, NHS satisfaction measures the overall composite assessment of the health care system, including "political support", that may differ from the evaluation of specific areas of the health system. Therefore, significant discrepancies might arise when health system assessments rely on different "satisfaction" measures. This has been especially true in the case of Spain: Evidence suggests that when health system satisfaction of Spaniards is compared to that of other Western countries, Spain ranks quite low, in the 12th position, just between Canada and the U.S. Nevertheless, at the same time, Spain is ranked in a top position by the World Health Organization measure of system responsiveness. ${ }^{3}$ If other indicators are used, aggregate evidence points out that three quarters of the Spanish population believe that the health system needs reforms, and

\footnotetext{
${ }^{2}$ Blendon et al. (2001).

3 Ibid.
} 


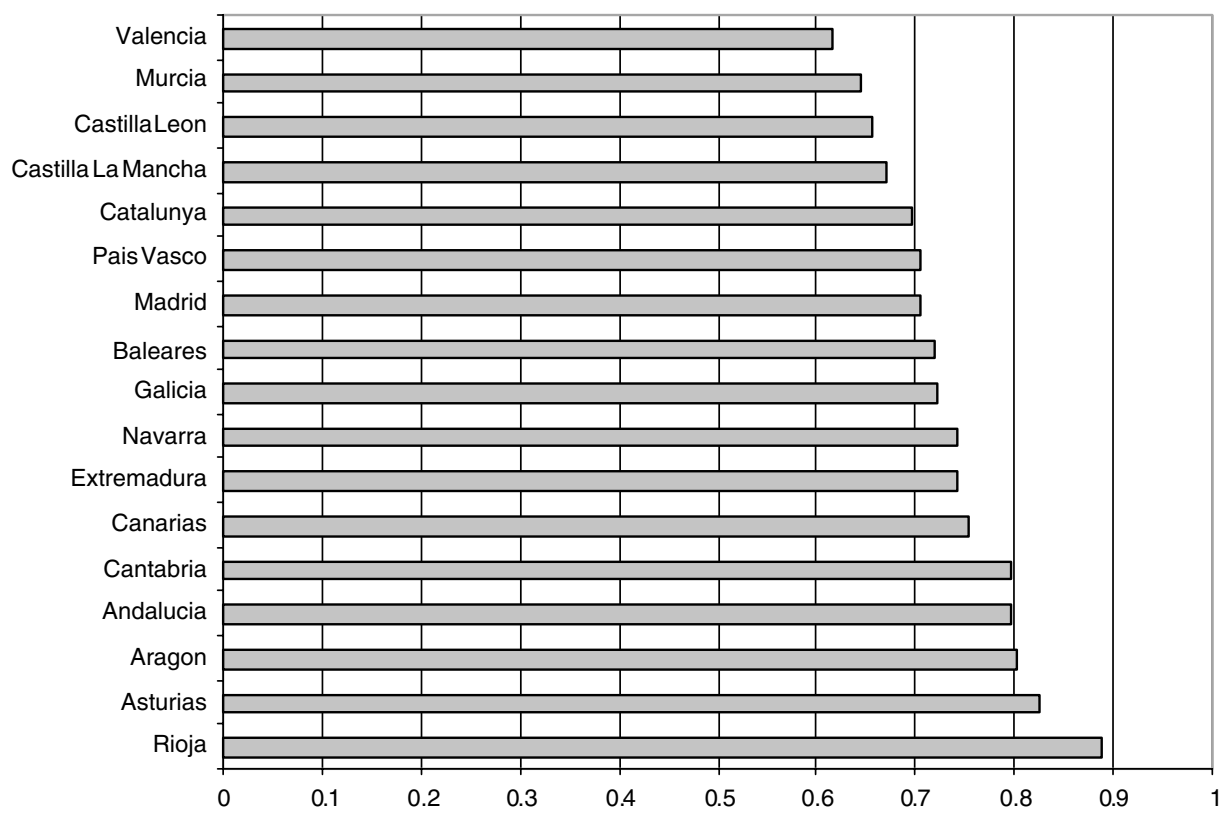

Figure 2. NHS satisfaction by Regional Health Service. Source: Health Care Barometer, 2002.

satisfaction with the health system has an average score of 6 in a range from 1 to 10 in the Health Care Barometer, 2002 (Figure 2). However, there was significant regional variability in 2002. On the other hand, the fact is that the market share of PHI is increasing so that already 16 per cent of the Spanish population has now PHI in 2005 (Figure 2). ${ }^{4}$

Attempts to measure the influence of satisfaction with the NHS and PHI are varied. Calnan et al. ${ }^{5}$ estimate a positive association using descriptive measures between health system dissatisfaction and the decision to purchase PHI in the U.K. The interpretation given is that the more unsatisfactory coverage of the NHS is, the larger the share of the private medical care. Some further evidence points out that satisfied patients are less likely to "shop around" for additional health care benefits. ${ }^{6}$ In other studies, satisfaction is used as a proxy measure of individual's utility of a unit of care. ${ }^{7}$ Interestingly, Hall and Preston ${ }^{8}$ examine the influence of individuals' attitudes towards health care spending priorities. Their findings suggest that PHI decision and attitudes towards the NHS influence each other.

\footnotetext{
${ }^{4}$ While 90 per cent of Spaniards would choose a public provider for primary, inpatient, and emergency care, on average 25 per cent would choose private health providers for specialist care if they could (Barometro Sanitario (2003)).

${ }^{5}$ Calnan et al. (1993).

${ }^{6}$ Stewart (1995).

${ }^{7}$ Carlsen and Grytten (2000).

${ }^{8}$ Hall and Preston (1999).
} 
At the same time, variables directly related to NHS perceived quality such as waiting times ${ }^{9}$ or perceived quality ${ }^{10}$ influence PHI purchase decisions.

In view of previous research, we hypothesize that satisfaction with the NHS and the decision to buy private health care are related. Their relationship stems not only from the fact that NHS perceived quality influences both variables but that possibly there are unobserved individual factors, such as political inclinations or family tradition, that determine NHS satisfaction and/or PHI purchase decisions.

This paper aims at examining empirically the simultaneous association between the purchase of PHI and satisfaction with the NHS in the context of Spain, a country that has consolidated an NHS system since the mid-1980s. We develop an empirical strategy to estimate the likelihood of having PHI and the likelihood of being satisfied with the NHS that controls for the potential endogeneity of NHS perceived and allows for the existence of correlation between the unobservable factors influencing both PHI purchase and satisfaction with the NHS.

We use data from the Health Care Barometer of 2002 containing records on the PHI decision, a measure of overall satisfaction with the NHS, and variables on individual characteristics.

We find that, after controlling by income, regional variability, socio-demographic variables, and a measure of perceived NHS quality, the purchase of PHI and satisfaction with the NHS are negatively correlated. Accordingly, the inability of the NHS to curb down dissatisfaction is associated with the development of the PHI market. This interpretation is consistent with the hypothesis of the "partial optingout" as one of the reasons behind the development of private health care sector.

The structure of the paper is the following: The next section summarizes some background literature on the theoretical determinants of opting-out and of satisfaction. The following section describes the empirical strategy and the data. The penultimate section reports the results obtained. The last section concludes.

\section{Background: "partial" opting-out and health system satisfaction}

\section{Preliminary evidence}

The relative weight of public and private health care is arguably determined among other factors by the extent to which individuals are satisfied with the health system. In some countries (possibly affluent), unsatisfied individuals may opt-out of (and stop paying for) certain services provided publicly and subscribe a PHI to cover some of their health care needs instead.

Maybe because in most countries "pure opting-out" is not possible - as contributions to finance the NHS continue no matter that the individual subscribed a PHI - the issue of opting out has received only limited attention. In particular, prior research has focussed on the connection between health care satisfaction and the individual's opting-out decision. In a study that is related to this issue,

\footnotetext{
${ }^{9}$ Epple and Romano (1996); Besley et al. (1999); Jofre-Bonet (2000a).

${ }^{10}$ Costa-Font and García (2003).
} 
654

Boeri et al. ${ }^{11}$ found that older individuals - who might only be interested in immediate gratification effects - and those relatively poorer - and hence exhibiting income effects are less likely to support a reduction in the welfare state while the young are for it. They also found that education does not exert an influence on welfare state support. Similarly, findings of studies examining on welfare state support evidence form the health care sector point towards a contemporaneous correlation of unobservable variables underpinning the association between NHS support and private health care. ${ }^{12}$ Other studies that have examined empirically government satisfaction in the U.S. conclude that both pecuniary and non-pecuniary issues influence government satisfaction. ${ }^{13}$

\section{NHS satisfaction: self-interested and collective determinants}

Health system satisfaction is a health system outcome measure increasingly used. It draws upon a wide individual normative evaluation of what an individual receives from the health system. Interestingly, there is evidence of significant heterogeneity in health system satisfaction among EU member states. ${ }^{14}$ Yet, whether NHS satisfaction trends "cause" or are "driven" by the expansion of PHI is still an open question. Privately insured individuals who do not use all NHS services may be less satisfied with the NHS. However, there may be altruistic reasons so that responses to satisfaction questions are influenced by "warm glow" according to the Andreoni ${ }^{15}$ terminology. ${ }^{16}$

NHS satisfaction can be explained from a variety of different theories. Selfrealization theories ${ }^{17}$ defend the idea of people climbing in their hierarchy of needs. Hence, PHI subscription might be an expression of an increasing demand for quality of care once "basic health care is assured". ${ }^{18}$ Other theories define satisfaction as the realization of an individual's expectations based on health care experienced, ${ }^{19,20}$ which explains why older individuals seem to be more easily satisfied as compared to young individuals. Furthermore, we cannot rule out the hypothesis that satisfaction with the NHS is an expression of regionally determined variables connected with individuals' political preferences or social values (e.g., family tradition).

The coexistence of PHI with the NHS is complex: First, governmental subsidies to private health care are controversial because some believe the money should rather be spent on improving the public health system. Second, individuals suffering the contention of publicly financed health (e.g., waiting lists) are more likely to be

\footnotetext{
${ }^{11}$ Boeri et al. (2001).

${ }^{12}$ Costa-Font and Jofre-Bonet (2005).

${ }^{13}$ Cebula and Paul (2002).

${ }^{14}$ Mossialos (1997).

15 Andreoni (1990).

16 "Warm glow" meaning that although the privately insured individual may not benefit directly as much from the NHS, he/she may experience some non-egoistic feelings towards it, improving the individual's satisfaction with the NHS.

${ }^{17}$ Maslow (1970).

${ }^{18}$ Cleary and McNeil (1988).

${ }^{19}$ Accordingly if $M_{i}^{*}$ measures the individual's medical care expectations and $M_{i}$ actual health care received, satisfaction is a function of both $S_{i}=f\left(M_{i}, M_{i}^{*}\right)$ so that $S_{M^{\prime}}>0$ and $S_{M^{*}}^{\prime}<0$.

${ }^{20}$ Linder-Pelz (1982); Hall and Dornan (1990).
} 
currently insured, as has been shown by Besley et al. ${ }^{21}$ and Propper, ${ }^{22}$ which has clear political implications. In this sense, ideological determinants may well influence individual decisions. Propper ${ }^{23}$ and Burchardt and Propper ${ }^{24}$ bring to the fore the role of non-economical determinants (such as political concerns) in explaining the demand for PHI. Propper found that beliefs against the public sector are associated with the purchase of PHI.

\section{The institutional environment}

The Spanish NHS provides universal and comprehensive coverage to the whole population including immigrants since 1986. Yet, unlike other NHS systems, since 2002, the Spanish health care system has been de-centralized so that health policy has been transferred to the administration of the 17 Autonomous Communities (ACs). ${ }^{25}$ Despite public coverage, PHI supplements the NHS in areas with problematic waiting lists and times for minor conditions, and has the attraction of offering better hotel services and other amenities. PHI usually offers a limited range of provider choice depending upon availability of private clinics. While PHI covers around the 16 per cent of the Spanish population in 2005 according to the Association of Spanish Private Insurers, ${ }^{26}$ in some relatively affluent areas such as Catalunya, Madrid, and the Balearics this share is approximately of over 25 per cent. Since 1999, Spain stopped the pre-existing long lasting tax relief on private health care for individually purchased policies, but the relief remained in place for corporately purchased policies. ${ }^{27}$ Nevertheless, employer-based health insurance, although expanding, is still not very common in Spain. Insurance premiums increase with age. In our data (see Table 1), 8.8 per cent of PHI in Spain is financed individually, 3.4 per cent is corporate subscribed and 2.9 per cent is publicly financed. In the two latter cases, individuals do not actually buy PHI out of their disposable incomes. Therefore, we have excluded those two groups when defining private helath insurance subscription using data from 2002.

\section{Empirical strategy and data}

\section{PHI and satisfaction: a simultaneous model}

\section{PHI decision}

To be able to estimate the effect that the NHS health care quality has on the health insurance purchase decision, we use a variation of the model in Jofre-Bonet ${ }^{28}$ (explained in more detail in the Appendix).

\footnotetext{
${ }^{21}$ Besley et al. (1998, 1999).

${ }^{22}$ Propper (2000).

${ }^{23}$ Burchardt and Propper (1999).

${ }^{24}$ Propper (1993).

${ }^{25}$ López-Casasnovas et al. (2005).

${ }^{26}$ UNESPA (2006).

${ }^{27}$ López-Nicolás et al. (2000).

28 Jofre-Bonet (2000a).
} 
The Geneva Papers on Risk and Insurance - Issues and Practice

656

Table 1 Variable definition, summary statistics, and expected sign

\begin{tabular}{|c|c|c|c|c|c|c|}
\hline \multirow[t]{2}{*}{ Variable name } & \multirow[t]{2}{*}{ Definition } & \multicolumn{3}{|c|}{ Type and summary statistics } & \multicolumn{2}{|c|}{$\begin{array}{l}\text { Expected sign of } \\
\text { relationship with } \\
\text { endogenous variables }\end{array}$} \\
\hline & & Type & Mean & $\begin{array}{l}\text { Standard } \\
\text { error }\end{array}$ & PHI & $\begin{array}{c}\text { NHS } \\
\text { satisfaction }\end{array}$ \\
\hline PHI & Respondent has PHI & Dummy & 0.09 & 0.005 & $\mathrm{~N} / \mathrm{A}$ & Jointly det. \\
\hline NHS quality & $\begin{array}{l}\text { Health care quality } \\
\text { perception }\end{array}$ & Continuous & 6.73 & 0.029 & - & + \\
\hline Satisfaction & NHS satisfaction index & Continuous & 6.13 & 0.036 & Jointly det. & $\mathrm{N} / \mathrm{A}$ \\
\hline Age & Respondents age & Continuous & 47.20 & 0.335 & $+1-$ & + \\
\hline Married & Respondent is married & Dummy & 0.649 & 0.009 & - & $+/-$ \\
\hline Male & Respondent is male & Dummy & 0.50 & 0.009 & $-/+$ & $-/+$ \\
\hline Illiteracy & $\begin{array}{l}\text { Respondent has no } \\
\text { schooling }\end{array}$ & Dummy & 0.10 & 0.118 & + & + \\
\hline $\begin{array}{l}\text { Income } \\
\text { (in logs) }\end{array}$ & Respondent's income & Continuous & 11.89 & 0.010 & + & $+1-$ \\
\hline \multicolumn{7}{|c|}{ Variables used as instruments } \\
\hline $\begin{array}{l}\text { NHS relative } \\
\text { use }\end{array}$ & $\begin{array}{l}\text { Respondents per cent } \\
\text { of use of outpatient and } \\
\text { inpatient care }\end{array}$ & Continuous & 0.79 & 0.050 & $\mathrm{~N} / \mathrm{A}$ & $\mathrm{N} / \mathrm{A}$ \\
\hline $\begin{array}{l}\text { Size of the } \\
\text { locality }\end{array}$ & $\begin{array}{l}\text { Size in milliards of the } \\
\text { locality }\end{array}$ & Continuous & 25.01 & 0.372 & $\mathrm{~N} / \mathrm{A}$ & $\mathrm{N} / \mathrm{A}$ \\
\hline Regions & $\begin{array}{l}17 \text { identifiers of each } \\
\text { autonomous community }\end{array}$ & Dummy & - & - & $\mathrm{N} / \mathrm{A}$ & $\mathrm{N} / \mathrm{A}$ \\
\hline
\end{tabular}

Let $V^{A}\left(\theta, p^{A}, q^{A}, y\right)$ be the expected utility of an individual with probability of illness $\theta$, purchasing health insurance of quality $q^{A}$ for a premium equal to $p^{A} q^{A}$, and with income $y$. Let the expected utility of the individual be $V^{P}(\theta, Q, y)$ if he does not buy health insurance and faces treatment by the public provider at quality $Q$. We let $d_{i j}$ be a variable that takes value 1 if the household $i$ of region $j$ purchases health insurance because the expected utility of doing so is greater than not doing so, and 0 if it does not. Then, the following expression holds:

$$
\begin{aligned}
& d_{i j}=1 \text { if } V_{i j}^{A}\left(\theta, p^{A}, q^{A}, y\right)-V_{i j}^{P}(\theta, Q, y)>0 \\
& d_{i j}=0 \text { if } V_{i j}^{A}\left(\theta, p^{A}, q^{A}, y\right)-V_{i j}^{P}(\theta, Q, y) \leqslant 0
\end{aligned}
$$

where $i$ stands for individuals $i=1,2, \ldots N_{j}$ and $j$ for regions.

Further, by assuming that $V_{i j}^{A}$ and $V_{i j}^{P}$ depend linearly on the exogenous variables and that they are distributed normally with 0 mean and $\sigma^{A}$ and $\sigma^{P}$ variances, respectively, the probability of buying insurance can be expressed as:

$$
\begin{aligned}
P\left(d_{i j}=1\right) & =P\left(\varepsilon_{i j}^{d}<\beta_{d} x_{i j}+\gamma_{d} Q_{j}+\eta_{d} C_{j}\right) \\
& =\Phi\left(\beta_{d} x_{i j}+\gamma_{d} Q_{j}+\eta_{d} C_{j}\right)
\end{aligned}
$$


where $\varepsilon_{i j}^{d}$ are the idiosyncratic factors behind the decision to buy private health; $\Phi$ denotes the standard normal distribution function; $x_{i j}$ are observable characteristics of household $i$ living in province $j$; $Q_{j}$ is a measure of the differential between the quality of public and private health care $Q-q^{A}$; and $c_{j}$ are variables capturing other supply characteristics in region $j .{ }^{29}$

\section{Satisfaction with the NHS}

Similarly, the individual is satisfied, $s_{i j}=1$, if the expected utility from the NHS, given the individual's idiosyncratic factors, $\varepsilon_{i j}^{\mathrm{s}}$, is above a threshold $u_{i j}$, and not, $s_{i j}=0$, if it is below:

$$
\begin{aligned}
& s_{i j}=1 \text { if } V_{i j}^{P}\left(Q y z ; \varepsilon_{i j}^{s}\right)-\bar{u}_{i j}>0 \\
& s_{i j}=0 \text { if } V_{i j}^{P}\left(Q y z ; \varepsilon_{i j}^{s}\right)-\bar{u}_{i j} \leqslant 0
\end{aligned}
$$

where again $i$ stands for individuals $i=1,2, \ldots N_{j}$ and $j$ for regions.

Again, by assuming linearity of $V_{i j}^{P}(Q, y, z)-u_{i j}$ with respect to the arguments that $u_{i j}$ is arbitrarily small, and that the idiosyncratic error term explaining individual variation is distributed normally, the probability of being satisfied with the NHS can be expressed as:

$$
\begin{aligned}
P\left(s_{i j}=1\right) & =P\left(\varepsilon_{i j}^{s}<\beta_{s} z_{i j}+\gamma_{s} Q_{j}+\eta_{s} C_{K}\right) \\
& =\Phi\left(\beta_{s} z_{i j}+\gamma_{s} Q_{j}+\eta_{s} C_{j}\right),
\end{aligned}
$$

where $\Phi$ denotes the standard normal distribution function; $z_{i j}$ are observable characteristics of household $i$ living in area $j ; Q_{j}$ is a quality measure of the NHS health-care services; and $c_{j}$ are variables capturing other supply characteristics in region $j$.

Finally, assuming linearity of the expected utilities with respect to their arguments, we can rewrite Equations (1) and (2) as:

$$
\begin{gathered}
d_{i j}^{*}=\beta_{d} x_{i j}+\gamma_{d} Q_{j}+\eta_{d} c_{K}+\varepsilon_{i j}^{d} \\
s_{i j}^{*}=\beta_{s} z_{i j}+\gamma_{s} Q_{j}+\eta_{s} c_{K}+\varepsilon_{i j}^{s}
\end{gathered}
$$

Further, we assume that the unobservables influencing PHI purchase are potentially correlated with the unobservables explaining satisfaction, that is, $\operatorname{corr}\left(\varepsilon_{i j}^{s}, \varepsilon_{i j}^{d}\right) \neq 0$. As usual, since $d_{i j}^{*}$ and $s_{i j}^{*}$ are not directly observable, we express them instead as dichotomous decision variables $d_{i j}$ and $s_{i j}$ that take value of 1 or 0 based on the survey information.

\section{The endogeneity of quality and the correlation between PHI and satisfaction}

Given the potential reasons for quality of care being endogenous (e.g., omitted variables, etc.), we want to contemplate the potential endogeneity of the NHS quality,

\footnotetext{
${ }^{29}$ In the data application, we approximate the differential between health-care providers using the perceived NHS quality $Q$ only.
} 
$Q_{j}$, in Equations (3) and (4) above. The rationale behind our endogeneity concern is the following: On the one hand, the number of private health care subscribers versus the number of the strictly public health system subscribers determines some aspects of the public health care system quality such as congestion. Congestion of the NHS materializes in waiting lists faced, length of contact time per patient, and even equipment and consumables available to patients. Thus, PHI purchase decisions and NHS quality are determined simultaneously. This makes quality endogenous in Equation (3). Equally, we believe that overall satisfaction and experienced quality are potentially determined simultaneously in that the unobservables explaining both outcomes are probably correlated. This makes NHS quality endogenous in Equation (4).

Note that we include NHS quality - as a proxy of the differential quality between providers - as a regressor in the PHI decision Equation (3) and not "satisfaction with the NHS" itself. The reason is, as argued previously, that we interpret satisfaction as a general approval of the health system beyond quality, while quality perceived is a service-specific evaluation, which we believe is what matters when making PHI purchase decisions. As also explained above, we do allow for correlation between the unobserved characteristics of the individual determining his quality perception and his declared level of satisfaction.

\section{The econometric strategy}

We estimate Equations (3) and (4) using increasingly sophisticated specifications:

First, we estimate the decision to buy PHI, Equation (3), by using both a probit model and an instrumental-variables probit model. The latter allows us to control for the potential endogeneity of the quality variable.

Second, we estimate Equation (4) using a probit model for the likelihood of being satisfied, both controlling and not controlling for the potential endogeneity of the NHS quality variable $Q .^{30}$

The two-stage probit models above are estimated following Maddala's ${ }^{31}$ application by Newey. ${ }^{32}$ In particular, we use the programs implementing the Amemiya's generalized least squares estimators of probit models with endogenous regressors as in Newey. ${ }^{33}$ The instruments used to estimate NHS quality are: size of town of residence; gender; regional dummies; and intensity of NHS health care use calculated as the proportion of NHS health services used out of total health services consumed.

Finally, to allow for correlation between the unobservables explaining both PHI and NHS satisfaction, we estimate a seemingly unrelated probit model using a two-stage method for simultaneous binary dependent variable equations in which one of the

\footnotetext{
${ }^{30}$ We tested different cutting points of the satisfaction variable and we selected the threshold of seven-orabove to indicate satisfaction. We did so to avoid the "conformist reactions" of the middle point bias rounded around the scores of five and six.

${ }^{31}$ Maddala (1983).

${ }^{32}$ Newey (1987).

${ }^{33}$ Ibid.
} 
endogenous variables is instrumented. To reduce unobserved heterogeneity and unobserved supply side systematic effects, we do include regional dummies when we estimate the model simultaneously.

\section{The data}

We use the Health care Barometer 2002, a survey representative of the Spanish population released in March 2003. The questionnaire was designed to examine individuals' perceptions of the Spanish NHS. The total sample size was 6,749 individuals, and it is even representative at the region-state or AC level. The database is publicly available at the web pages of the Ministry of Health and Consumption in Spain (www.msc.es) and it contains records on the individual satisfaction with the NHS, the use of private and public health care services as well as PHI purchase.

From the database, we obtain the following key variables:

\section{(a) Quality of care}

We construct the measure of the NHS quality of care as composite measure equal to the average of three perceived quality scores: that experienced in primary care and paediatrics; that of specialized care; and that of inpatient care. The structure of the questions used can be translated as: "Please, use a scale from 10 "totally satisfactory" to 1 "totally unsatisfactory" 34 to measure the care quality of each of the following public health care components: Primary care and paediatrics (in question \#11); Specialized care (in question \#13); Inpatient care (in question \#14)".

(b) Health care satisfaction with the NHS services

We corrected the measure of satisfaction with the NHS from the individuals' answers from a question on the general perception of the NHS. This question aims at eliciting the individual's global evaluation of the health care system, which we assume surpasses the individual's own experience. The question used reads as follows: "Are you satisfied with how the health system works in Spain? To respond use a card where 1 means that you are very unsatisfied and 10 very satisfied".

The distribution and the density of this variable are displayed in Figure 3. Interestingly, the vast majority of the population provides a rate that ranges between four and eight. In our empirical application, we choose to create a satisfaction binary variable that takes value 1 if the answer to this question is above seven, and zero otherwise. This was done to distinguish dissatisfaction given that the mean score was about 6.

\section{(c) PHI subscription}

To construct the measure of privately insured subscription, we used the answer to the following question: "Could you please tell me if you are a subscriber of any of the different forms of health insurance that appear in this card?

- NHS

- Special statutory insurance adhered to the NHS

- Private health insurance individually subscribed or corporately entitled."

\footnotetext{
${ }^{34}$ Originally, the question was stated as from 1 best to 10 worst, but we have rescale it to 1 worst to 10 best.
} 


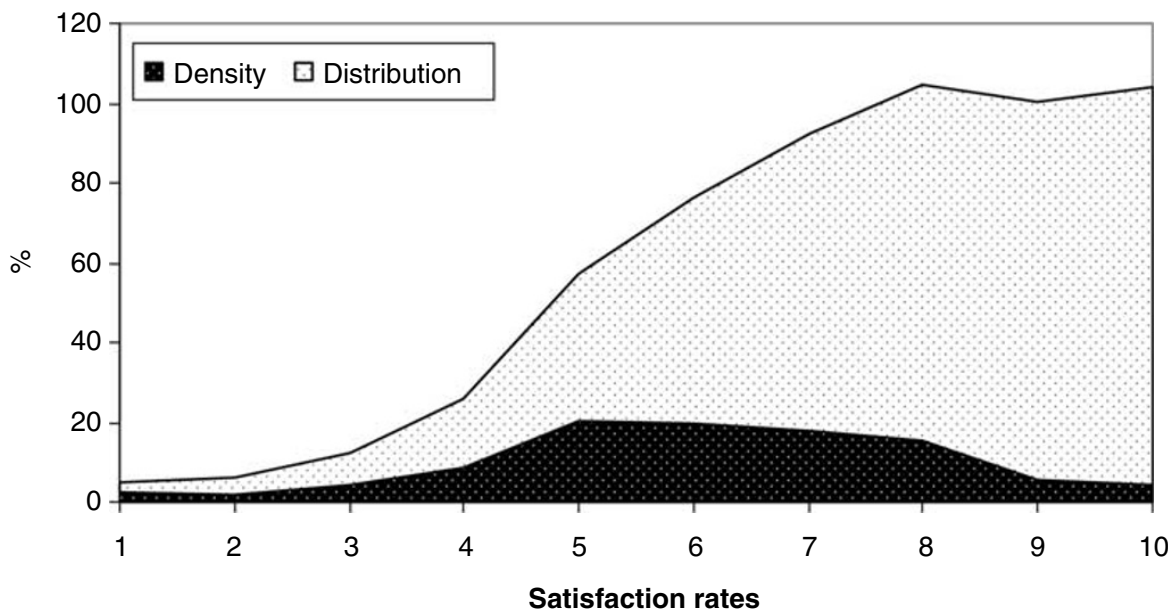

Figure 3. The distribution (cumulative percentage) and density (percentage) of NHS satisfaction in Spain 2002. Source: Barometro Sanitario, 2002, Ministerio de Sanidad y Consumo.

\section{Descriptive statistics}

In Table 1, we provide our variable definitions and report some descriptive statistics. We also report the expected effects of each variable on the decisions of PHI purchase and satisfaction with the NHS variables based on prior literature.

As we can observe, for our sample 8.8 per cent of the population report being privately insured. The average level of satisfaction with the NHS is 6.13 , and the composite NHS quality score has a mean of 6.73 . The average age of the respondents is $47.7,64$ per cent of the sample are married, 50 per cent male, the average monthly income is 146,385 (former) pesetas (about $€ 880$ ). We constructed a measure of relative use of NHS as opposed to privately financed health care services as the proportion of NHS outpatient or inpatient services versus privately paid health care one. The mean of this measure was 79 per cent, meaning that on average, respondents used the NHS services four out of five times they needed health care. Finally, the average city size of residence of the respondents was 25,000 inhabitants.

\section{Expected signs}

As an exercise, we comment here the expected signs of some of the relationships between PHI, NHS satisfaction, and NHS quality and some other independent variables. We expect that a higher perception of NHS quality should reduce the probability of purchasing PHI and promote a higher NHS satisfaction. Age has usually a double effect as it approximates individuals' health care needs but, since insurance companies take into account individuals' age in estimating their insurance premiums, a counter effect may exist. ${ }^{35}$ With respect to satisfaction, the elderly have been reported to be generally less satisfied with their health

\footnotetext{
${ }^{35}$ Besley et al. (1999).
} 
system. ${ }^{36}$ Being married might proxy a larger household size and therefore a more restricted income to purchase PHI while the effect on NHS satisfaction is difficult to determine. ${ }^{37}$ PHI has been shown to be a normal good ${ }^{38}$ and therefore we expect income to be associated positively with PHI.

\section{Results}

We first provide the results concerning the demand for PHI decision. Table 2 provides the estimate of each variable marginal effect, its standard error, as well as its significance using stars.

As we can see from Table 2, assuming that quality is endogenous has a very important impact on its coefficient on the likelihood of having PHI: The specification that does not control for the endogeneity of the NHS quality provides an almost null but positive and significant effect on the probability of purchasing PHI. In contrast, the specification that corrects for NHS quality possible endogeneity indicates that a 10 per cent increase in the perceived quality of the NHS reduces the decision to buy PHI by 1.2 per cent. ${ }^{39}$

Regardless of the specification, age appears to be significant and suggests that the older the individual is, the more likely he is to subscribe a PHI policy, which is consistent with age being a proxy of individual health. As expected, being married, which is correlated with having children, makes PHI for the whole family more expensive and therefore less likely. Income displays a positive effect on the probability of insurance and the estimated elasticity is 1.12 indicating that PHI is a normal and even a relatively luxury good, consistent with previous studies too. Overall, the pseudo $R^{2}$ tests indicate that the specification where we treat NHS quality as endogenous performs slightly better.

We next examine the estimates of the NHS satisfaction Equation (4), reported in Table 3.

We estimate two probit models of being satisfied with the NHS as defined above: The first model treats NHS quality as an exogenous variable and the other does not. ${ }^{40}$

${ }^{36}$ Blendon et al. (2001).

${ }^{37}$ Calnan et al. (1993).

${ }^{38}$ Costa-Font and García (2002).

${ }^{39}$ Weak exogeneity test on quality: We apply the test of weak exogeneity to the NHS quality variable in the first specification of Table 2 following the Smith (1987) approach. The test is based on a simplified likelihood ratio (SLR) and compares the difference between the loglikelihood values of the specification where quality is exogenous versus that where it is treated as endogenous and it multiplies the difference by two. This statistic follows a $\chi_{\mathrm{g}}^{2}(\alpha)$ distribution, where $\mathrm{g}$ is the number of potentially endogenous regressors and $\alpha$ the level of significance. In our case, $\operatorname{SLR}=-2(-790.11+761.27)=57.68$ and thus well above the values of the $\chi_{\mathrm{g}}^{2}(\alpha)$ distribution with one degree of freedom at the 5 per cent and 1 per cent level of significance $-\chi_{1}^{2}()=3.84$ and $\chi_{1}^{2}()=6.64$, respectively. According to this result, we would reject the exogeneity of the quality variable at the 5 per cent and 1 per cent levels of significance.

${ }^{40}$ We also apply the weak exogeneity test to the NHS quality variable when estimating Equation (4) or the probability of being satisfied. As with the case of PHI purchase, we found that we do reject the null hypothesis of exogeneity of the NHS quality variable at the 5 per cent and 1 per cent level as $S L R=-2(-1521.76+132.23)=403.06$. 
The Geneva Papers on Risk and Insurance - Issues and Practice

662

Table 2 Probability of having private health insurance (PHI)

\begin{tabular}{|c|c|c|c|c|}
\hline \multirow{2}{*}{$\begin{array}{l}\text { Dependent variable } \\
\text { PHI }\end{array}$} & \multicolumn{2}{|c|}{ Exogenous quality } & \multicolumn{2}{|c|}{ Endogenous quality (*) } \\
\hline & $d F / d x$ & Standard error & $d F / d x$ & Standard error \\
\hline NHS quality & $0.008^{*}$ & 0.04 & $-0.119 * *$ & 0.034 \\
\hline Age & $0.005^{* *}$ & 0.002 & $0.005^{*}$ & 0.002 \\
\hline Age2 & -0.0003 & 0.00002 & -0.00027 & -0.00022 \\
\hline Married & $-0.02 * *$ & 0.008 & $-0.048 * *$ & 0.0174 \\
\hline Income (logs) & $0.08^{* *}$ & 0.01 & $0.11 * *$ & 0.013 \\
\hline Regional dummies & \multicolumn{2}{|c|}{ No } & \multicolumn{2}{|c|}{ No } \\
\hline Log likelihood & -790.11 & & -761.27 & \\
\hline Pseudo- $R^{2}$ & 0.07 & & 0.085 & \\
\hline Likelihood ratio test $\chi_{5}^{2}$ & 157.02 & & 141.6 & \\
\hline
\end{tabular}

*Indicates significance at the 5 per cent level and **significance at the 1 per cent.

Notes: NHS quality of care is instrumented using the following variables: Gender; indicator variables for region-state (Autonomous Community); intensity of use of NHS (share of visits to an NHS provider out of all medical visits); and an indicator variable for the variable size of town being missing.

The $F$-tests of joint significance are significantly different from zero at 1 per cent for both equations.

Interestingly, in both specifications, quality of care is significantly and positively associated with NHS satisfaction but the coefficient is 0.004 in the former and 0.155 in the latter. This suggests a lower perception of NHS quality translates into a lower satisfaction level as some studies had already indicated. ${ }^{41}$

The effect of age smoothes when quality of care is treated as an endogenous variable. Thus, controlling for individual experience on NHS quality makes the age effect on NHS satisfaction disappear as suggested by some studies. ${ }^{42}$ Being male decreases the probability of being dissatisfied, although it is only significant when NHS quality is treated as an endogenous variable. This is in accordance to previous findings, which pointed out that men tend to exhibit lesser satisfaction than women. ${ }^{43}$

The results of estimating Equations (3) and (4) simultaneously taking into account the potential correlation of their error terms are reported in Table 4.

As we can observe, the coefficient measuring the correlation between the residuals of both equations, $\rho$, is significant and equals -0.08 - when quality of care is treated as exogenous. Therefore, the likelihood of having PHI and being satisfied with the NHS displays a negative and significant correlation.

If we concentrate on the specification of the bivariate model where we control for the potential endogeneity of quality (right most panel), we see that income is now negatively associated to NHS satisfaction - unlike the insignificance result obtained in Table 3 - while it continues to be positively associated to having PHI.

\footnotetext{
${ }^{41}$ Cleary and McNeil (1988).

${ }^{42}$ Hall and Dornan (1990).

${ }^{43}$ Ibid.
} 
Table 3 Probability of being satisfied with the NHS in Spain

\begin{tabular}{|c|c|c|c|c|}
\hline \multirow{2}{*}{$\begin{array}{l}\text { Dependent variable: } \\
\text { NHS satisfaction }\end{array}$} & \multicolumn{2}{|c|}{ Exogenous quality } & \multicolumn{2}{|c|}{ Endogenous quality (*) } \\
\hline & $d F / d x$ & Standard error & $d F / d x$ & Standard error \\
\hline NHS quality & $0.004 * *$ & 0.001 & $0.155^{* *}$ & 0.020 \\
\hline Age & $-0.01 * *$ & 0.003 & -0.001 & 0.007 \\
\hline Age2 & $1.1 \times 10^{-4 * *}$ & $2 \times 10^{-5}$ & $1.2 \times 10^{-4 * *}$ & $2 \times 10^{-5}$ \\
\hline Married & 0.0258 & 0.0193 & 0.039 & 0.046 \\
\hline Income (logs) & -0.0473 & 0.0176 & -0.024 & 0.043 \\
\hline Illiteracy & 0.0002 & 0.0016 & 0.003 & 0.004 \\
\hline Male & -0.0073 & 0.0162 & $-0.116^{* *}$ & 0.042 \\
\hline Regional dummies & \multicolumn{2}{|c|}{ No } & \multicolumn{2}{|c|}{ No } \\
\hline Log likelihood & -1521.7686 & & -1320.23 & \\
\hline Pseudo- $R^{2}$ & 0.06 & & 0.19 & \\
\hline Likelihood ratio test $\chi_{5}^{2}$ & 225.85 & & 620.8 & \\
\hline
\end{tabular}

*Indicates significance at the 5 per cent level and **significance at the 1 per cent.

Notes: NHS quality of care is instrumented using the following variables: Gender; indicator variables for region-state (Autonomous Community); intensity of use of NHS (share of visits to an NHS provider out of all medical visits); and an indicator variable for the variable size of town being missing.

The $F$-tests of joint significance are significantly different from zero at 1 per cent for both equations.

One interpretation of this result is that individuals who are more affluent are less likely to be satisfied with the NHS as they might feel they pay higher taxes the greater the quality is, but benefit relatively little from it as they are more likely to buy PHI.

Maybe a bit surprisingly, the variable NHS perceived quality becomes insignificant in the NHS satisfaction equation. We interpret this result as meaning that other observed and unobserved factors may pick up all its effect when estimated jointly with having PHI. Quality continues to have a highly significant and negative coefficient on the probability of purchasing PHI. Age displays a nonlinear effect on NHS satisfaction and on the probability of buying PHI. Although the linear term in the NHS satisfaction equation is negative, it is positive in the PHI decision, while the quadratic terms is positive in both equations. Nevertheless, for our age range, the global effect of age is positive on both equations although of different magnitude. In particular, at the mean age of 47.7 , the effect of age on the probability of being satisfied is 7.14 and on the probability of buying PHI 46.53. Being married seems not to influence the probability of being satisfied with the NHS but affects negatively that of buying PHI.

\section{Discussion}

In this paper, we explore whether there exists an association between supplementary PHI and satisfaction with the NHS. Our work intends to provide some insight on the mechanisms behind the hypothetical joint expansion of the market for PHI and the declared dissatisfaction with the NHS by an important share of the population. 
The Geneva Papers on Risk and Insurance - Issues and Practice

664

Table 4 NHS satisfaction and the probability of having private health insurance

\begin{tabular}{|c|c|c|c|c|}
\hline \multirow[b]{2}{*}{ Dependent variable: NHS satisfaction } & \multicolumn{2}{|c|}{ Exogenous quality } & \multicolumn{2}{|c|}{ Endogenous quality (*) } \\
\hline & Coefficient & Standard error & Coefficient & Standard error \\
\hline NHS quality & $0.53 *$ & 0.02 & 0.71 & 1.03 \\
\hline Age & $-0.033 * *$ & 0.009 & $-0.036^{* *}$ & 0.009 \\
\hline Age2 & $0.0004 *$ & 0.0008 & $0.0004 *$ & 0.00015 \\
\hline Married & 0.09 & 0.06 & 0.10 & 0.059 \\
\hline Income (logs) & -0.06 & 0.05 & $-0.12 *$ & 0.05 \\
\hline Illiteracy & 0.06 & 0.05 & 0.07 & 0.09 \\
\hline Male & -0.024 & 0.050 & -0.02 & 0.05 \\
\hline Intercept & $39.90 *$ & 15.48 & -33.795 & 4.91 \\
\hline Regions & \multicolumn{2}{|c|}{ Yes } & \multicolumn{2}{|c|}{ Yes } \\
\hline Dependent variable: Having PHI & Coefficient & Standard error & Coefficient & Standard error \\
\hline NHS Quality & $-0.105^{* *}$ & 0.032 & $-0.180^{* *}$ & 0.012 \\
\hline Age & $0.035 * *$ & 0.013 & $0.05 * *$ & 0.013 \\
\hline Age2 & -0.002 & 0.001 & $0.02 * *$ & 0.002 \\
\hline Married & -0.160 & 0.086 & $-0.33 * *$ & 0.093 \\
\hline Income (logs) & $0.603 * *$ & 0.084 & $0.586^{* *}$ & 0.088 \\
\hline Illiteracy & $0.04 * *$ & 0.006 & -0.95 & 0.12 \\
\hline Intercept & 39.90 & 15.48 & $85.32 * *$ & 6.572 \\
\hline Regions & \multicolumn{2}{|c|}{ Yes } & \multicolumn{2}{|c|}{ Yes } \\
\hline Wald Test $\chi_{46}^{2}$ & 471.95 & & & \\
\hline$\rho$ & -0.08 & 0.04 & & \\
\hline
\end{tabular}

*Indicates significance at the 5 per cent level and **significance at the 1 per cent.

Notes: NHS quality of care is instrumented using the following variables: Gender; indicator variables for region-state (Autonomous Community); intensity of use of NHS (share of visits to an NHS provider out of all medical visits); and an indicator variable for the variable size of town being missing.

Previous studies ${ }^{44}$ examined exclusively the effect of having PHI on the political support for the NHS - rather than the satisfaction with it. In this paper, we take advantage of a rich database from Spain, which includes data on PHI, NHS quality, and satisfaction with the NHS. We model the effect of NHS quality on both the probability of buying PHI and being satisfied with the NHS taking into account: (a) that the unobservable factors explaining PHI and being satisfied may be correlated (e.g., political inclination, local and familiar traditions, etc.); and (b) that quality may be endogenous to both decisions.

In accordance with previous evidence, ${ }^{45}$ we find that a reduction in the quality of the NHS has an expansive effect on the market for supplementary PHI. Similarly, we identify a significantly positive income effect explaining the demand for PHI, and furthermore, as in previous studies, we find that PHI is a luxury good with an associated elasticity slightly over the unity.

\footnotetext{
${ }^{44}$ Hall and Preston (1999); Costa-Font and Jofre-Bonet (2005).

45 Jofre-Bonet (2000a, b); Costa-Font and García (2003).
} 
Our findings indicate that NHS satisfaction and having PHI are negatively associated. We also find that NHS satisfaction is negatively associated to an individual's income while, as noticed, it is positively associated to having PHI. The negative sign in the former might very well indicate that affluent individuals perceive higher quality at the NHS as a "negative signal" as they may interpret higher NHS quality as higher taxes to fund a service they do not use so much if they are insured (having double coverage).

Finally, our final joint estimates of PHI and being satisfied with the NHS suggest that, when controlling quality endogeneity and their correlation, NHS quality is insignificant in explaining satisfaction with the NHS. This result is consistent with the hypothesis that NHS evaluation takes a wider collective (or system) perspective that surpasses individual's quality evaluations but is somewhat puzzling.

Our results indicate there is substantial scope for reform in health systems so as to keep individuals satisfied with the NHS and allow at the same time the development of the private insurance sector. Yet, our results suggest that the purchase of PHI may indicate that the NHS is failing to satisfy the demand for differentiated perceived quality dimensions (e.g., amenities) from an heterogeneous population.

Last, but not least, we find that unobservable factors explaining PHI expansion and NHS satisfaction are negatively associated. Altogether, we interpret our results as an indication that individuals flee the NHS because they experience NHS qualities that are below their thresholds but that there is a reinforcing effect by which fleeing the NHS harms their satisfaction with the NHS even further.

\section{Acknowledgements}

We are grateful to the comments of two anonymous referees as well as to Christophe Courbage and Marisol Rodriguez for their help with writing this paper. Joan Costa-Font is grateful to the Spanish Ministry of Science and Technology for the project SEJ2005-06270 and Generalitat de Catalunya for the project 2005SGR-460.

\section{References}

Andreoni, J. (1990) 'Impure altruism and donations to public goods: A theory of warm-glow giving', The Economic Journal 100(401): 464-477.

Barometro Sanitario (2003) Barometro Sanitario, Ministerio de Sanidad y Consumo, Madrid.

Besley, T., Hall, J. and Preston, I. (1998) 'Private and public health insurance in the UK', European Economic Review 42: 491-497.

Besley, T., Hall, J. and Preston, I. (1999) 'The demand for private health insurance: Do waiting lists matter?,' Journal of Public Economics 72: 155-181.

Blendon, J., Kim, M. and Benson, J.M. (2001) 'The public vs. the World Health Organization on health system performance', Health Affairs 20(3): 10-20.

Boeri, T., Borsch-Supan, A. and Tabellini, G. (2001) 'Would you like to shrink the welfare state? A survey of European citizens', Economic Policy 32: 9-50.

Burchardt, T. and Propper, C. (1999) 'Does the UK have a private welfare class?', Journal of Social Policy 28: 643-665.

Calnan, M., Cant, M. and Gabe, J. (1993) Going Private: Why People Pay for their Health, Buckingham, UK: Open University.

Carlsen, F. and Grytten, J. (2000) 'Consumer satisfaction and supplier induced demand', Journal of Health Economics 19(5): 731-753. 
Cebula, R. and Paul, C. (2002) 'A note on the determinants of public dissatisfaction with government', American Journal of Economics and Sociology 61(2): 495-501.

Cleary, P.D. and McNeil, B.J. (1988) 'Patient satisfaction as an indicator of quality care', Inquiry 25(3): $25-36$.

Costa-Font, J. and García, J. (2002) 'Cautividad y demanda de seguros sanitarios privados', Cuadernos Económicos De ICE 55: 71-88.

Costa-Font, J. and García, J. (2003) 'Demand for private health insurance: How important is the quality gap?' Health Economics 12(7): 587-599.

Costa-Font, J. and Jofre-Bonet, M. (2005) The 'Secession of the Wealthy': Demand for Private Health Insurance and Support for the National Health System, LSE Health and Social Care, Discussion Paper Series No. 19 ..

Epple, D. and Romano, R.E. (1996) 'Ends against the middle: Determining public service provision when there are private alternatives', Journal of Public Economics 62(3): 297-325.

Hall, J. and Preston, I. (1999) Public and Private Choice in UK Health Insurance, WP 98-4, Institute of Fiscal Studies.

Hall, J.A. and Dornan, M.C. (1990) 'Patient socio-demographics characteristics as predictors of satisfaction with medical care: A meta-analysis', Social Science Medicine 30(7): 811-818.

Jofre-Bonet, M. (2000a) 'Public health care and private insurance demand: The waiting time as a link', Health Care Management Science 3(1): 51-71.

Jofre-Bonet, M. (2000b) 'Health care: Private and/or public provision', European Journal of Political Economy 16(3): 469-489.

Linder-Pelz, S. (1982) 'Toward a theory of patient satisfaction', Social Science Medicine 16(5): $577-582$.

López-Casasnovas, G., Costa-Font, J. and Planas, I. (2005) 'Diversity and regional inequalities: Assessing the outcomes of the Spanish "system of health care services", Health Economics 14(Suppl): S221-S235.

López-Nicolás, A., García, J., López-Casasnovas, G. and Puig, J. (2000) Es posible reducir el gasto sanitario a través del subsidio a los seguros sanitarios privados?, Working Paper Universitat Pompeu Fabra, Centre de Recerca en Economia i Salut, 21.

Maddala, G.S. (1983) Limited-Dependent and Qualitative Variables in Econometrics, Econometric Society Monographs in Quantitative Economics, Cambridge, UK: Cambridge University Press.

Maslow, A.H. (1970) Motivation and Personality, New York: Harper and Row.

Mossialos, E. (1997) 'Citizens' views on health care systems in the 15 member states of the European union', Health Economics 6(2): 109-116.

Newey, W. (1987) 'Efficient estimation of limited dependent variable models with endogenous explanatory variables', Journal of Econometrics 36: 230-251.

Propper, C. (1993) 'Constrained choice sets in the UK demand for private medical insurance', Journal of Public Economics 51(3): 287-307.

Propper, C. (2000) 'The demand for private health care in the UK', Journal of Health Economics 19(6): $855-876$.

Smith, R. (1987) 'Testing for exogeneity in limited dependent variable models using a simplified likelihood ratio statistic', Journal of Applied Econometrics 2(3): 237-245.

Stewart, MA. (1995) 'Effective physician-patient communication and health outcomes', Canadian Medical Association Journal 152(9): 1423-1433.

UNESPA (2006) 'Area Estadistica', http://www.icea.es, accessed in December 2005.

\section{Appendix}

We based our empirical strategy on a reduced form inferred from the combination of the PHI purchase published elsewhere ${ }^{46}$ with a model of the likelihood of

\footnotetext{
46 Jofre-Bonet (2000a).
} 
being satisfied with the NHS developed for this paper. We summarize the model as follows:

\section{Private health insurance}

We assume that purchasing a PHI is the result of an expected utility maximization process. A typical consumer can be ill with an individual probability $\theta$. In order to recover to a healthy state, he or she has to consume a unit of treatment of quality $q$, where $q \in\left[q^{B}, q^{A}\right]$ and $q^{B}$ is the minimum quality required for the patient to recover and $q^{A}$ the maximum quality available. ${ }^{47}$ With the existence of a PHI market, the treatment options available are of quality $q$ at a cost of $\pi$ from the private provider, and of quality $Q$ from a free-at-source NHS.

Let us assume that $U(y)$ is the typical consumer's utility function when he is healthy. $U\left(\right.$.) depends positively on his income at a decreasing marginal rate, that is, $U^{\prime}(y) \geqslant 0$ and $U^{\prime \prime}(y) \leqslant 0$. Let us assume that $u(q, y)$ is the utility achieved when the individual is sick and receives a treatment of quality $q$ having income $y$. We also assume that $u($.$) is$ an increasing and concave function of the income. In addition, for a given level of wealth $y$, the utility increases with the quality of the treatment, that is, $u_{y}(q, y) \geqslant 0$, $u_{y y}(q, y) \leqslant 0$ and $u_{y q}(q, y) \leqslant 0$. Arbitrage guarantees that the highest quality, $q^{A}$, is provided in the insured health care sector.

If $\pi$ is the price of the premium paid by the consumers, then the average premium has to be equal to the expected cost of a consumer. This is $\pi=p^{A} q^{A}$.

Therefore, the possible satisfaction levels of the consumer are:

- $U\left(y-p^{A} q^{A}\right)$, if healthy but having subscribed to a health insurance plan.

- $u\left(q^{A}, y-p^{A} q^{A}\right)$, if ill and insured, receiving a treatment of quality $q^{A}$.

- $U(y)$, if healthy but not choosing to buy PHI.

- $u(Q, y)$, if ill and receiving a treatment of quality $Q$ within the NHS

Since the individual's probability of being ill is $\theta$, his/her expected utility if he/she buys $\mathrm{PHI}$ is:

$$
V^{A}\left(\theta, p^{A}, q^{A}, y\right)=\theta u\left(q^{A}, y-p^{A} q^{A}\right)+(1-\theta) U\left(y-p^{A} q^{A}\right)
$$

If the individual does not get PHI, the expected utility is:

$$
V^{P}(\theta, Q, y)=\theta u(Q, y)+(1-q) U(y)
$$

Therefore, the typical consumer will only subscribe to a PHI plan whenever:

$$
V^{A}\left(\theta, p^{A}, q^{A}, y\right) V^{P}(\theta, Q, y)
$$

Thus, buying health insurance, among other factors, depends on: The public health care quality $Q$ compared to that of care received under health insurance $q^{A}$; the individual (household) characteristics such as income level, $y$; and, health status or risk of illness, $\theta$. Even though this result is a simplification, it confirms a logical intuition about what determines the purchase of health insurance: income; (household) individual characteristics; and, the quality differential between the free-at-source NHS and the private health sector.

\footnotetext{
${ }^{47}$ We assume that if the treatment works, full recovery is guaranteed.
} 
A priori, if health is a normal good and higher quality of health care is associated to better outcomes, we expect that an increase in the quality differential between the private and the public health providers will increase the demand for PHI. ${ }^{48}$

NHS satisfaction and NHS quality

We assume that an individual feels satisfied with the NHS when the expected utility of using the NHS health care system is above a certain threshold, $u$, given the individual characteristics, $z$, including income:

$$
E V^{P}(Q, y, z)>\bar{u}
$$

We also assume that the lower the NHS quality of care perceived by the individual, the lower the satisfaction of such an individual with the NHS, $V_{Q}^{P}(Q, y, z) \geqslant 0$; that expected utility is an increasing concave function of the income, $V_{y}^{P}(Q, y, z) \geqslant 0$, $V_{y y}^{P}(Q, y, z) \leqslant 0$; and that for a given level of wealth $y$, the expected utility increases with the quality of the treatment, that is, $V_{y q}^{P}(Q, y, z) \leqslant 0$.

\section{About the Authors}

Joan Costa-Font is Associate Professor of Economics at the University of Barcelona and Research Fellow at the London School of Economics (LSE Health).

Mireia Jofre-Bonet is a Lecturer in Health Economics at the Department of Economics, City University, London and Research Fellow at the London School of Hygiene and Tropical Medicine. 